\title{
Are attitudes towards smoking different for males and females?
}

\author{
Valerie Clarke, Victoria White, Joan Beckwith, Ron Borland, David Hill
}

\begin{abstract}
Objective - To examine whether men and women have similar or different attitudes to smoking with regard to the illnesses caused by smoking and conditions (eg, stress) thought to be helped by smoking, advantages and disadvantages of giving up smoking, the effects of smoking on others, attitudes to anti-smoking advertisements and smoking restrictions at work, support for quitting, and reasons for resuming smoking after quitting.

Design - Analysis of survey data looking at the relative importance of differences between the gender-based categories of male/female and the smoking-based categories of smoker/ex-smoker/neversmoker.
\end{abstract}

Data collection - Interview data collected from a sample of $\mathbf{2 9 8 5 4}$ adult Australians in the years 1983 to 1989 .

Results-Responses to most questions indicated that women and men smoked for essentially the same reasons. The differences in attitudes to smoking between the smoking categories of neversmoker, ex-smoker, and current smoker were greater than the differences between the gender-based categories of male and female. In those cases where there were significant gender differences, these were essentially consistent with a situational explanation of gender-related differences in attitudes, expectations, and behaviours.

Conclusion-In Australia, both women and men who smoke have essentially similar beliefs about smoking. Therefore it should be feasible to develop educational campaigns for this country that are broadly applicable to both women and men.

(Tobacco Control 1993; 2: 201-8)

\section{Introduction}

From 1974 to 1989 there was a marked decline in the proportion of adult Australian men who were regular smokers, but only a slight decline in the proportion of adult Australian women who were regular smokers. ${ }^{1,2}$ Similar trends have been reported in the United States (US) ${ }^{3}$ and third world countries. ${ }^{4}$ The question is, why do these differences exist?

Explanations of gender differences in smok- ing are many and varied. Most of the popular explanations have been comprehensively reviewed in two recent papers by Grunberg, Winders and Wewars ${ }^{5}$ and Waldron ${ }^{6}$ making it unnecessary to provide a further review. The authors of both papers recognise that there might be biological differences between women and men which affect the impact of nicotine on their bodies, but they see the effects of these factors as lacking clear empirical validation and as being less important than social-cultural factors. Grunberg et al..$^{5}$ provide a clear and concise summary of the existing research, but warn that "there currently is no single convincing explanation for the varied gender differences that exist in tobacco use and we are not prepared to remedy that situation" (p 146).

In contrast, Waldron ${ }^{6}$ suggests that gender differences in smoking patterns in western countries reflect differences in the changing roles of women, particularly in relation to their power status, personal characteristics and experiences, and appraisals of the costs and benefits of smoking. Although neither of these reviews provides an adequate explanation of the observed gender differences in smoking patterns, they both contain clues to a possible resolution of this issue.

The emphasis on differences in roles and experiences in the Waldron paper provides the first clue. The second clue arises from both reviews' observation that gender differences in smoking behaviour may be partly the effect of commonly observed relationships between gender and other socio-cultural variables, such as religious observance, participation in the military, educational level, occupational level, employment status, or deviant or rebellious personality arising from life experiences. Drawing from these two points it is proposed that the observed gender differences in smoking are not an independent effect of gender, but are a by-product of an array of sociocultural factors which correlate with gender. If this is the case there is no need to ask why there are gender differences in smoking. Attention should be re-directed to focus on the more general question of why people smoke, and to identify the environmental and experiential factors that relate to smoking for both women and men.

This argument can be developed drawing on the social psychological theories of gender differences proposed by $\mathrm{Bem}^{7}$, Deaux ${ }^{8,9}$ and 
Eagly $^{10}$. Bem ${ }^{7}$ argues that individuals vary in the extent they organise their perceptions of the world according to gender schema or ideas, or some other set or sets of concepts or ideas. However, the importance of gender schema differs from one situation to another and from one individual to another. For example, if study participants are asked about their perceptions of male and female smokers, the question makes the issue of gender salient and may increase the degree of difference reported. At an individual level, some people, and possibly some researchers, are interested in gender differences whereas others attach little importance to gender, focussing on individuals as people rather than as females or males.

These ideas are consistent with those of Deaux,,$^{8,9}$ who argues that the attitudes and expectations of women and men differ as they are allocated to different social categories, the categories of female and male. Each of these categories is associated with different expectations, attitudes, and behaviours. These social categories serve as a basis for each individual to assess the likely behaviour of others and of themselves, and as such they influence the likelihood of engaging in and reporting that behaviour. As in Bem's formulation, the salience of gender-based categories varies, being more relevant to some individuals than others and in some situations than in others.

Gender is only one example of a social category. Women and men are also members of a wide range of other categories including occupational categories and, possibly, smoking categories. The relative impact of the expectations associated with different categories varies depending on the salience of the category. In the absence of other information, gender-based categories often affect our expectations, but when other relevant information is available, the impact of gender categories is reduced or disappears. For example, research shows that in occupationally relevant situations where both occupational category and gender category information is available, the occupational category information has a greater impact on expectations, attitudes, and behaviours than does the gender category information. ${ }^{11}$ If the impact of an occupational category on attitudes, expectations, and behaviours is greater than the impact of a gender category when occupational issues are considered, it is likely that the impact of a smoking category may also be greater than the impact of a gender category when one is concerned with issues relating to smoking. There is some evidence for this position. Borland ${ }^{12}$ found that some sex differences in slip-up contexts for smoking cessation attempts disappeared when only women who were in the work force were included in the analyses.

Expectations about the behaviour of others often reflect expectations about the categories to which they belong. Eagly ${ }^{10}$ argues that people who belong to one category, such as a gender category, are often more likely to be expected to belong to another category, such as a specific occupational category, because it has been observed than many members of the first category belong to the second category. Further, as a result of belonging to a particular category individuals have category-relevant experiences and develop the requisite skills. As a result of having these skills it is often assumed that they chose to belong to that category and that they hold the stereotypical attitudes and beliefs associated with category membership.

These general arguments can be related to smoking behaviour. In this case, the smoking categories of never-smoker, ex-smoker, and current smoker will provide more information about a person's attitudes and beliefs about smoking than will the gender-based categories of female and male. Further, where there are gender differences in attitudes and beliefs about smoking, these will be the product of life experiences rather than gender, and as such will mirror commonly observed gender differences in occupational and social roles.

\section{Methods}

SAMPLE DESIGN

Between 1983 and 1989, interviews were conducted with a sample of 29854 adults, aged 16 years and over. Of the total sample, $48 \%$ were male and $52 \%$ female. In 1983, 1986, and 1989 there was a national sample, while in the intervening years the sample was limited to the state of Victoria. In each year for both the national and Victorian samples interviews were conducted at weekends within electoral subdivisions which were chosen at random within specified strata that included State for the national surveys and urban/rural categories for both national and Victorian surveys. Within each of these subdivisions one elector's name was selected at random and the residence adjoining this elector was the first dwelling contacted. Further adjoining dwellings were approached until the required number of interviews (usually 10) was obtained. If the quota was unfilled the interviewer began calling back to those houses where nobody had been at home. If the quotas were unfilled at the end of the first day, interviewers returned the next day for a second call-back and if this still did not fill the quota, adjoining residences were approached until the quota was filled. One interview per household was conducted and interviewers adhered to a respondent selection key rotating among various age/sex categories. If that household's selected person refused to be interviewed, a substitute from that household was not found. Replacement interviewees were needed in $39 \%$ of cases in $1983,42 \%$ in 1986 , and $55 \%$ in 1989. Assessments of the sociodemographic representativeness of the annual samples have indicated a close correspondence to the Australian Census data. ${ }^{13}$

\section{INTERVIEW SCHEDULE}

Questions on smoking were embedded in an omnibus survey conducted by a market research organisation. The other items in the survey were relevant to research projects unrelated to smoking. This issue-neutral 
agency was used to minimise possible bias in self-reported smoking behaviour, ${ }^{14}$ although there is extensive evidence of the validity of self-reports of smoking frequency. ${ }^{15,16}$ In addition to general questions on smoking status and demographic characteristics, subsets of respondents were asked about their perceptions of the relationship between smoking and health, the possible role of passive smoking, and their degree of approval of social controls in the forms of restriction on advertising of cigarettes or the banning of smoking in the workplace. Smokers and ex-smokers were asked about the relative advantages and disadvantages of quitting, their perceived social support for quitting, reasons for any lapse of their intention to be non-smokers, and the type of reasons/contexts which led quitters to resume smoking. Questions were asked as open-ended questions to which respondents volunteered replies. These were recorded on pre-coded response sheets. The sample for any particular comparison varies from 2242 to 19378. The sample sizes are indicated in the tables. Sample sizes varied as different questions were asked in different years of data collection.

\section{ANALYSES}

The data were collapsed across geographical boundaries (states of Australia) and over the data collection times (1983 to 1989) to evaluate gender differences in reasons for smoking, quitting, or relapsing. This procedure may have obscured some minor differences arising from time- and state-specific educational campaigns, but the intention was to identify robust differences which were not a function of transient influences. Preliminary analyses suggest that the responses for the national samples and the state samples are consistent.

The analyses involved cross-tabulations of smoking status (never-smoker, ex-smoker, and current smoker), and gender (male, female) with each of the smoking attitudinal and behavioural variables. Alpha was set at 0.001 . Statistical significance was assessed using hierarchical logistic regression for nonparametric data. All analyses were completed using the Statistical Package for Social Sciences (SPSSx) on a mainframe computer.

\section{Results}

SMOKING STATUS

Of the 15247 women in the sample, $29 \%$ were smokers, $17 \%$ were ex-smokers, and $54 \%$ had never smoked regularly. Of the 14108 men in the sample, $34 \%$ were smokers, $28 \%$ were exsmokers, and $38 \%$ had never smoked. Thus, there were more women who had never smoked regularly and more men who were smokers or ex-smokers.

\section{SMOKING AND HEALTH}

The percentages of women and men within each of the relevant smoking categories who gave a positive response to each of the smoking-related questions are presented in table 1, together with the chi-square values for the variable of interest by gender, by smoking status, and by the interaction of gender and smoking status. Asterisks indicate that the chisquare values are significant at the 0.001 level.

In response to the question "In your opinion are there any illnesses caused by smoking?", there was a significant effect for smoking status (chi-square $=607.32, \mathrm{df}=2, \mathrm{p}<0.001$ ) with positive responses occurring more frequently among never-smokers and ex-smokers than among current smokers. There were no significant gender differences (chi-square $=5.61$, $\mathrm{df}=1, \mathrm{~ns})$.

When respondents were asked to state the relevant illnesses, lung cancer was the disease most frequently given, being mentioned almost twice as frequently as the next two most

Table 1 Percentages of smokers in each of the smoking status and gender groups giving positive responses to questions concerned with the relationship between smoking and health $(n=19378) . M=$ males; $F=$ females

\begin{tabular}{|c|c|c|c|c|c|c|c|c|c|}
\hline \multirow[b]{3}{*}{ Health issue } & \multicolumn{6}{|c|}{ Smoking status } & \multirow{2}{*}{\multicolumn{3}{|c|}{ Chi-square value }} \\
\hline & \multicolumn{2}{|c|}{ Never-smoker } & \multicolumn{2}{|c|}{ Ex-smoker } & \multicolumn{2}{|c|}{ Smoker } & & & \\
\hline & $M$ & $F$ & $M$ & $F$ & $M$ & $F$ & $\begin{array}{c}\text { Smoking } \\
\text { status }\end{array}$ & Gender & Interaction \\
\hline $\begin{array}{l}\text { One or more illnesses } \\
\text { caused by smoking }\end{array}$ & 95.6 & 94.1 & 92.0 & 91.7 & 82.7 & 82.0 & $607.32^{\star}$ & 5.61 & $552.24^{\star}$ \\
\hline $\begin{array}{l}\text { Specific illnesses caused } \\
\text { Lung cancer } \\
\text { Heart disease } \\
\text { Emphysema } \\
\text { Unspecified cancers } \\
\text { Other specific cancers } \\
\text { Respiratory complaints } \\
\text { Bronchitis } \\
\text { Blood pressure } \\
\text { Stroke } \\
\text { Circulatory problems } \\
\text { Coughs } \\
\text { Asthma }\end{array}$ & $\begin{array}{r}70.4 \\
32.8 \\
30.2 \\
18.5 \\
15.8 \\
13.5 \\
11.5 \\
8.5 \\
7.1 \\
6.4 \\
6.2 \\
5.9\end{array}$ & $\begin{array}{r}65.4 \\
29.6 \\
34.6 \\
18.3 \\
16.0 \\
13.2 \\
14.6 \\
6.1 \\
6.9 \\
5.5 \\
6.6 \\
11.1\end{array}$ & $\begin{array}{r}60.1 \\
33.5 \\
31.3 \\
15.4 \\
14.4 \\
14.7 \\
13.8 \\
7.3 \\
7.1 \\
6.9 \\
5.6 \\
6.0\end{array}$ & $\begin{array}{r}62.7 \\
34.5 \\
38.3 \\
16.2 \\
14.0 \\
13.6 \\
17.5 \\
6.8 \\
8.2 \\
6.6 \\
6.8 \\
9.4\end{array}$ & $\begin{array}{r}51.5 \\
31.4 \\
27.2 \\
15.8 \\
12.8 \\
9.4 \\
9.8 \\
6.0 \\
6.1 \\
5.1 \\
3.9 \\
4.3\end{array}$ & $\begin{array}{r}50.4 \\
31.2 \\
33.0 \\
16.0 \\
14.9 \\
9.2 \\
13.1 \\
5.4 \\
7.2 \\
5.6 \\
3.8 \\
7.1\end{array}$ & $\begin{array}{c}405.84^{\star} \\
11.09^{\star} \\
24.50^{\star} \\
21.64^{\star} \\
32.33^{\star} \\
77.37^{\star} \\
37.23^{\star} \\
14.22^{\star} \\
3.04 \\
9.18 \\
48.99^{\star} \\
40.57^{\star}\end{array}$ & $\begin{aligned} & 8.32 \\
& 3.64 \\
& 62.25^{\star}<1 \\
&< 1 \\
&<1 \\
&<1 \\
& 44.89^{\star} \\
& 14.44^{\star} \\
& 1.75 \\
&<1 \\
& 1.42 \\
& 107.17^{\star}\end{aligned}$ & $\begin{aligned} & 19.62^{\star} \\
& 6.71 \\
& 2.05 \\
< & 1 \\
& 4.44 \\
< & 1 \\
< & 1 \\
& 4.99 \\
& 3.75 \\
< & 1 \\
& 1.65 \\
& 2.99\end{aligned}$ \\
\hline Are illnesses helped? & 16.7 & 15.7 & 23.1 & 22.8 & 34.0 & 33.6 & $404.27^{\star}$ & $<1$ & $<1$ \\
\hline $\begin{array}{l}\text { Specific conditions helped } \\
\text { Nerves } \\
\text { Stress } \\
\text { Weight problems }\end{array}$ & $\begin{array}{l}9.9 \\
3.0 \\
1.6\end{array}$ & $\begin{array}{l}8.4 \\
2.4 \\
1.8\end{array}$ & $\begin{array}{r}14.0 \\
3.9 \\
1.9\end{array}$ & $\begin{array}{r}14.1 \\
4.4 \\
2.5\end{array}$ & $\begin{array}{r}21.9 \\
6.8 \\
3.0\end{array}$ & $\begin{array}{r}21.9 \\
5.2 \\
3.1\end{array}$ & $\begin{array}{r}303.96^{\star} \\
63.83^{\star} \\
20.33^{\star}\end{array}$ & $\begin{array}{l}1.05 \\
3.58 \\
0.91\end{array}$ & $\begin{array}{l}2.39 \\
3.18 \\
0.52\end{array}$ \\
\hline
\end{tabular}

${ }^{\star} \mathrm{p}<0.001$ 
frequently mentioned diseases: heart disease and emphysema. Less than $20 \%$ of the sample mentioned other specific cancers, unspecified cancers, respiratory complaints and bronchitis, while less than $10 \%$ of the sample mentioned blood pressure, stroke, circulatory problems, coughs, and asthma. Other problems which were mentioned by less than $5 \%$ of the sample (in most cases less than $1 \%$ of the sample) included complications during pregnancy, ulcers, liver complaints, teeth problems, headaches, poor general health, and other unspecified illnesses.

Nine illnesses were mentioned for which there were significant smoking status differences : lung cancer, emphysema, unspecified cancers, other specific cancers, respiratory complaints, bronchitis, blood pressure, coughs, and asthma. The most striking differences occurred for lung cancer which was mentioned by markedly more never-smokers than ex-smokers and more ex-smokers than current smokers (chi-square $=405.84, \mathrm{df}=2$, $\mathrm{p}<0.00001$ ). In all other cases there was a clear difference between never-smokers and smokers, but the position of the ex-smokers varied, sometimes being more similar to the never-smokers and sometimes more similar to the smokers. There were three illnesses for which there were no significant smoking status differences: heart disease, stroke, and circulatory problems.

For four illnesses there were significant gender differences. More women than men stated that smoking was related to ernphysema (chi-square $=62.25, \quad \mathrm{df}=1, \quad \mathrm{p}<0.00001$ ), bronchitis (chi-square $=44.89, \mathrm{df}=1, \mathrm{p}<$ 0.00001 ) and asthma (chi-square $=107.17$, $\mathrm{df}=1, \mathrm{p}<0.00001$ ), while more men than women suggested that smoking was related to high blood pressure (chi-square $=14.44, \mathrm{df}=$ $1, p=0.0001)$. In addition there was a smoking status by gender interaction for lung cancer (chi-square $=19.62, \mathrm{df}=2, \mathrm{p}<0.001$ ).
Less than a third of respondents believed that there were health problems which could be helped by smoking. Predictably, fewer never- and ex-smokers than smokers supported this belief. Of those conditions mentioned, the most commonly cited one was "nerves", followed by stress and weight. No differences existed between women and men within the smoking categories.

\section{ADVANTAGES OF GIVING UP SMOKING}

All smokers and ex-smokers were asked "What do you think would be the main advantages to you, if you gave up smoking?" This was asked as an open-ended question, with no prompts or assistance. Several answers could be provided. The percentages of smokers and ex-smokers who provided each of a set of possible precoded responses are provided in table 2 . This table presents the main effects of smoking status and gender but, as none of the interactions for variables reported in tables 2,3 , or 4 were significant, the chi-square values are omitted from the tables.

Both smokers and ex-smokers identified the same advantages of giving up smoking. The most important ones, identified by more than $10 \%$ of respondents, were feeling more healthy, saving money, and improving breathing and fitness. Less frequent advantages, mentioned by less than $5 \%$ of respondents, included avoiding the smell of tobacco smoke, setting a good example to children, avoiding cancer, heart disease or stroke, getting on top of the habit, and not polluting the air for nonsmokers.

There were significant differences between ex-smokers and smokers for six items. More of the smokers suggested that quitting would make them feel more healthy (chi-square = 80.29 , df $=1, p<0.001$ ), save money (chisquare $=103.96, \mathrm{df}=1, \mathrm{p}<0.001)$, and avoid cancer (chi-square $=11.98, \mathrm{df}=1, \mathrm{p}<0.001$ ),

Table 2 Percentages of smokers in each of the smoking status and gender groups volunteering each possibility as an advantage or disadvantage of giving up smoking $(n=29455) . M=$ males, $F=$ females

\begin{tabular}{|c|c|c|c|c|c|c|}
\hline & \multicolumn{4}{|c|}{ Smoking status } & \multirow{2}{*}{\multicolumn{2}{|c|}{ Chi-square value }} \\
\hline & \multicolumn{2}{|c|}{ Ex-smoker } & \multicolumn{2}{|c|}{ Smoker } & & \\
\hline & $M$ & $F$ & $M$ & $F$ & $\underset{\text { status }}{\text { Smoking }}$ & Gender \\
\hline \multicolumn{7}{|l|}{ Advantages of giving up } \\
\hline $\begin{array}{l}\text { Feel more healthy } \\
\text { Save money }\end{array}$ & 18.4 & $\begin{array}{l}16.0 \\
132\end{array}$ & $\begin{array}{l}22.0 \\
18.9\end{array}$ & $\begin{array}{l}24.8 \\
206\end{array}$ & $\begin{array}{r}80.29^{\star} \\
103.96^{\star}\end{array}$ & 1.21 \\
\hline Improve breathing/fitness & 10.7 & 8.3 & 11.3 & 10.2 & 5.75 & $10.84^{\star}$ \\
\hline Reduce coughs/colds & 4.3 & 2.6 & 1.6 & 2.1 & $48.30^{\star}$ & 2.53 \\
\hline Avoid smell of tobacco smoke & 2.4 & 3.4 & 1.2 & 1.0 & $29.27^{\star}$ & $15.47^{\star}$ \\
\hline Good example to children & 0.8 & 1.4 & 1.0 & 1.4 & $<1$ & 8.05 \\
\hline Avoid cancer & 1.1 & 1.1 & 1.8 & 1.6 & $11.98^{\star}$ & $<1$ \\
\hline Avoid heart disease/stroke & 1.1 & 1.1 & 1.2 & 0.9 & $<1$ & 1.28 \\
\hline Get on top of the habit & 1.0 & 1.2 & 0.6 & 0.6 & $11.83^{\star}$ & $<1$ \\
\hline Avoid polluting non-smokers' air & 0.7 & 1.2 & 0.6 & 1.0 & 1.37 & 8.54 \\
\hline Other advantages & 4.3 & 4.8 & 3.6 & 3.6 & 8.29 & $<1$ \\
\hline \multicolumn{7}{|l|}{ Disadvantages of giving up } \\
\hline Put on weight & 5.5 & 5.4 & 7.4 & 13.5 & $108.85^{\star}$ & $65.25^{\star}$ \\
\hline Make irritable & 2.8 & 1.7 & 10.3 & 11.2 & $459.46^{\star}$ & \\
\hline Cause craving & 2.0 & 1.7 & 2.9 & 3.3 & $22.84^{\star}$ & $<1$ \\
\hline Make social situations difficult & 1.0 & 1.8 & 1.3 & 1.1 & $<1$ & 1.56 \\
\hline Hard to cope with stress & 0.6 & 0.7 & 2.8 & 3.7 & $124.12^{\star}$ & 7.05 \\
\hline Hard to cope with boredom & 0.4 & 0.6 & 1.7 & 1.7 & $57.81^{\star}$ & $<1$ \\
\hline Difficult to concentrate & 0.3 & 0.2 & 0.8 & 0.5 & $14.73^{\star}$ & 3.90 \\
\hline Make dizzy/light headed & 0.1 & 0.2 & 0.3 & 0.4 & 5.02 & 2.62 \\
\hline Other & 1.5 & 2.1 & 2.5 & 2.8 & $13.46^{\star}$ & 3.01 \\
\hline
\end{tabular}

${ }^{\star} \mathrm{p}<0.001$ 
while more of the ex-smokers were concerned about avoiding the smell of tobacco smoke (chi-square $=29.27, \mathrm{df}=1, \mathrm{p}<0.001$ ) and getting on top of the habit (chi-square $=11.83$, $\mathrm{df}=1, \mathrm{p}<0.001)$.

There were significant gender differences on two items. The first item, improving breathing and fitness, was mentioned by more men than women $\quad$ (chi-square $=10.84, \quad \mathrm{df}=1, \quad \mathrm{p}<$ 0.001 ). The second item, avoiding the smell of tobacco smoke, was mentioned by more female ex-smokers than male ex-smokers (chisquare $=15.47, \mathrm{df}=1, \mathrm{p}<0.001)$.

\section{DISADVANTAGES OF GIVING UP SMOKING}

Smokers and ex-smokers were asked "What do you think would be the main disadvantages if you gave up smoking?". The single most popular reason was only mentioned by about $9 \%$ of respondents. For six of the eight disadvantages there were significant differences between smokers and ex-smokers. In all cases the reasons were mentioned more frequently by the smokers: putting on weight (chi-square $=108.85, \mathrm{df}=1, \mathrm{p}<0.001$ ), making one irritable (chi-square $=459.46, \mathrm{df}=1$, $\mathrm{p}<0.001$ ), causing craving (chi-square $=$ 22.84, $\mathrm{df}=1, \mathrm{p}<0.001$ ), making it hard to cope with boredom (chi-square $=57.81, \mathrm{df}=$ $1, \mathrm{p}<0.001$ ), and difficult to concentrate (chisquare $=14.73, \mathrm{df}=1, \mathrm{p}<0.001$ ). There were only significant gender differences on one item. More women than men believed that the major disadvantage of giving up smoking was that they would put on weight (chi-square $=65.25$ $\mathrm{df}=1, \mathrm{p}<0.001)($ see table 2$)$

\section{PASSIVE SMOKING}

Responses to questions relating to attitudes towards smoking are presented in table 3. Significantly more never-smokers and exsmokers than current smokers believed that the health of non-smokers could be damaged by other people's smoke (chi-square $=522.56$, $\mathrm{df}=2, \mathrm{p}<0.00001$ ). There were no significant gender differences on this item.

\section{ANTI-SMOKING ADVERTISING}

Although over two-thirds of the sample approved of advertising campaigns to persuade people not to smoke, more never-smokers than ex-smokers, and more ex-smokers than smokers gave such approval (chi-square = 228.84, $\mathrm{df}=2, \mathrm{p}<0.00001)$. There were no significant gender differences (chi-square $=$ $3.19, \mathrm{df}=1, \mathrm{~ns}$ ).

\section{RESTRICTIONS ON SMOKING}

There were both smoking status and gender differences in the responses to specific questions about controlling smoking in the work place. In relation to the location of smoking, more never-smokers than ex-smokers and more ex-smokers than smokers believed that smoking should not be allowed anywhere,

Table 3 Percentages of respondents in each of the smoking status and gender groups giving each answer to questions about attitudes to smoking $(n=3477) . M=$ males, $F=$ females, $S=$ smokers, $N S=$ non-smokers

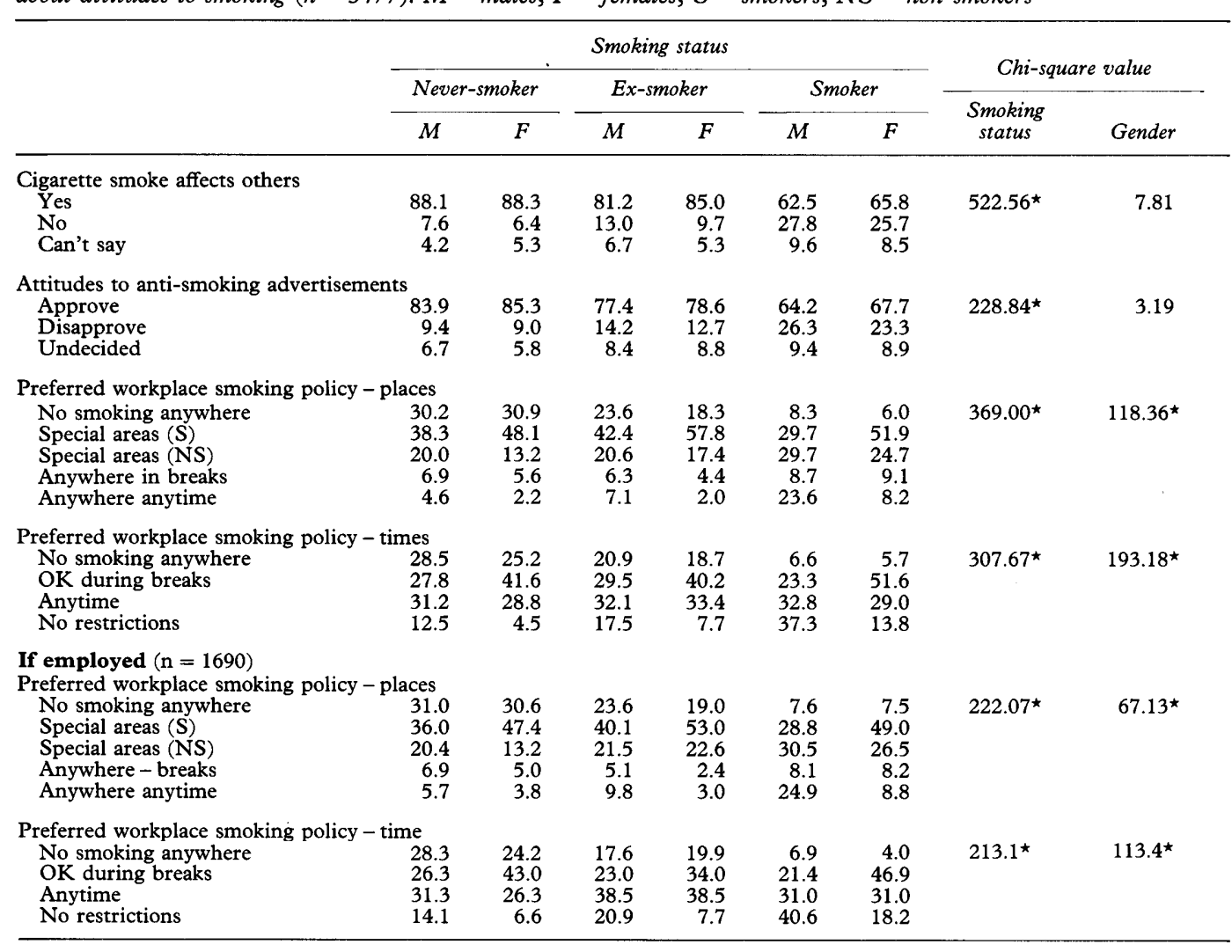


while more smokers believed there should be no restriction on smoking at work. The neversmokers and ex-smokers more often suggested that there should be special areas for smokers (chi-square $=369.00, \mathrm{df}=8, \mathrm{p}<0.0001$ ). In relation to gender differences, a higher proportion of male smokers opposed restrictions, while women were more likely to favour special areas for smokers (chi-square $=118.36, \mathrm{df}=$ $4, \mathrm{p}<0.001)$. Similar patterns emerged in relation to the time at which people should be allowed to smoke at work. Never-smokers and ex-smokers favoured more restrictions than smokers (chi-square $=307.67, \mathrm{df}=6, \mathrm{p}<$ 0.0001 ), and more women than men favoured more restrictions (chi-square $=193.18, \mathrm{df}=$ $3, \mathrm{p}<0.0001)$. Given that attitudes towards smoking policies at work might be influenced by the employment status of the respondent, the analyses were replicated using the subsample of those respondents who were in paid employment. Similar results were obtained (see table 3).

\section{POTENTIAL SUPPORT FOR QUITTING}

Among smokers, both women and men perceived the greatest amount of social support for their giving up would come from their spouse or partner, and the next most helpful person would be their mother, followed by their daughter and son (see table 4). There were significant gender differences in that more men $(43 \%)$ than women $(35 \%)$ expected to receive support from their spouse or partner, and more men (9\%) than women (5\%) expected to receive support from their workmates. On the other hand more women expected to find their daughter $(25 \%$ of women and $18 \%$ of men) or son $(24 \%$ of women and $17 \%$ of men) in favour of their giving up (chi-square $=30.20, \mathrm{df}=1, \mathrm{p}<$ 0.001 , and chi-square $=42.63, \mathrm{df}=1, \mathrm{p}<$ 0.001 , respectively).

Table 4 Perception of attitudes of relatives and friends towards the smokers' quitting expressed as the percentages who gave a positive response $(n=4994)$

\begin{tabular}{lccc}
\hline Person & Males & Females & Chi-square \\
\hline In favour of the smoker quitting & & \\
Partner & 42.5 & 34.5 & $33.75^{\star}$ \\
Mother & 28.0 & 32.2 & 10.47 \\
Daughter & 18.3 & 24.7 & $30.20^{\star}$ \\
Son & 17.0 & 24.2 & $42.63^{\star}$ \\
Father & 17.6 & 20.1 & 5.41 \\
Friends & 13.5 & 14.8 & 1.71 \\
Doctor & 8.2 & 8.5 & 0.10 \\
Other relative & 7.2 & 9.3 & 6.65 \\
Workmate & 8.9 & 4.8 & $33.28^{\star}$ \\
Sister & 5.6 & 6.1 & $<1$ \\
Brother & 4.0 & 4.6 & $<1$ \\
Against the smoker quitting & & \\
Partner & 2.9 & 3.1 & $<1$ \\
Friends & 2.7 & 2.5 & $<1$ \\
Workmates & 1.7 & 0.7 & 8.46 \\
Son & 0.6 & 0.6 & $<1$ \\
Brother & 0.6 & 0.1 & 5.84 \\
Father & 0.4 & 0.3 & $<1$ \\
Mother & 0.3 & 0.5 & $<1$ \\
Other relative & 0.4 & 0.5 & $<1$ \\
Doctor & 0.3 & 0.4 & $<1$ \\
Sister & 0.3 & 0.3 & $<1$ \\
\hline ^ & & & \\
p $<0.001$ & & & \\
& & &
\end{tabular}

Table 5 Percentages of male and female smokers offering each reason/context for resuming smoking after making an attempt to stop smoking (subjects gave several responses) $(n=2242)$

\begin{tabular}{lccc}
\hline Reason & Males & Females & Chi $i$-square \\
\hline When drinking alcohol & 32.3 & 14.2 & $102.02^{\star}$ \\
Socialising & 24.4 & 24.1 & 0.03 \\
Just drifted back & 25.8 & 20.3 & 9.50 \\
Contact with smokers & 18.2 & 22.5 & 6.31 \\
Craving too much & 11.7 & 15.3 & 6.51 \\
Job worries & 11.7 & 5.0 & $31.79^{\star}$ \\
Withdrawal symptoms & 9.9 & 13.4 & 6.87 \\
When drinking coffee & 7.0 & 12.4 & $18.83^{\star}$ \\
One wouldn't hurt & 8.8 & 10.3 & 1.37 \\
Money worries & 4.5 & 5.9 & 2.11 \\
Family arguments & 3.6 & 8.3 & $21.96^{\star}$ \\
Studies & 3.4 & 3.1 & 0.15 \\
Nagging & 3.3 & 5.6 & 7.18 \\
To lose weight & 3.3 & 8.4 & $26.90^{\star}$ \\
Personal illness & 2.4 & 4.3 & 6.56 \\
Tempted by smokers & 2.1 & 4.0 & 6.51 \\
Family illness & 2.0 & 5.8 & $21.03^{\star}$ \\
\hline
\end{tabular}

$\star \mathrm{p}<0.001$

Very few smokers expected that there would be resistance to their giving up. The persons most likely to be against giving up were spouses or partners, of which $3.0 \%$ expected to meet some discouragement (see table 4). There were no gender differences in the perceptions of those against the smoker quitting.

\section{QUITTING}

There were no significant differences between female and male smokers in the number of times they reported having tried to quit (women $=2.22, \quad$ men $=2.32, \quad t=0.95$, $\mathrm{df}=135, \mathrm{~ns})$. For 11 of the 17 reasons or contexts offered for resuming smoking after making a quit attempt, there were no gender differences (see table 5). There were two reasons which were given more frequently by men than by women: when drinking alcohol, suggested by $32 \%$ of men and $14 \%$ of women (chi-square $=102.02, \mathrm{df}=1, \mathrm{p}<0.001$ ), and job worries, suggested by $12 \%$ of men and $5 \%$ of women (chi-square $=31.79, \mathrm{df}=1, \mathrm{p}<$ 0.001). Four reasons/contexts were more frequently offered by women than by men: when drinking coffee $($ men $=7 \%$, women $=$ $12 \%$, chi-square $=18.83, \mathrm{df}=1, \mathrm{p}<0.001)$, family arguments $($ men $=4 \%$, women $=8 \%$, chi-square $=21.96, \mathrm{df}=1, \mathrm{p}<0.001$ ), to lose weight $($ men $=3 \%$, women $=8 \%$, chi-square $=26.90, \mathrm{df}=1, \mathrm{p}<0.001$ ), and family illness $($ men $=2 \%$, women $=6 \%$, chi-square $=$ 21.03, df $=1, \mathrm{p}<0.001$ ).

OVERVIEW OF THE RELATIVE IMPACT OF GENDER AND SMOKING CATEGORIES

Of 42 separate analyses using the combined variables of gender and smoking status, there were 33 where the differences associated with smoking status were markedly greater than the differences associated with gender, seven where the differences associated with gender were greater than those associated with smoking status, and two where there was little or no difference. 


\section{Discussion}

SMOKING STATUS

The findings are consistent with those of previous research which indicates a higher proportion of smokers among males than females worldwide,,$^{1-6,14}$ and also a higher proportion of ex-smokers among males than among females while there are more females who have never smoked. ${ }^{1-6,17,18}$

\section{HEALTH RISKS}

In relation to health beliefs, the differences between never-smokers, ex-smokers, and smokers were markedly greater than the differences between women and men within any of these categories. Overall, smoking status was more strongly related to smoking beliefs, attitudes, and reasons for smoking or relapse than was membership in the category of women or men, suggesting that the stereotypes or categorical expectations associated with smoking status are more strongly associated with one's beliefs about smoking than are stereotypes or categorical expectations associated with gender.

In the analyses of reasons for smoking and reasons for resuming smoking after making a quit attempt, none of the interactions of smoking status and gender was significant. This indicates that these two sets of categories are operating independently, and that responses for each smoking status did not differ by gender even in the instances where both factors were significant, adding further weight to the argument that, at a psychological level, smoking status and gender are associated with separate categorical expectations. However, the few gender differences that do emerge have some practical implications both for smoking education aimed at preventing people from taking up smoking and for education campaigns directed towards current smokers.

The gender differences which do exist are consistent with the suggestion that they are a reflection of differential gender distribution in social and occupational roles and hence with the opportunities to develop attitudes and expectations consistent with those roles. For example, the greater preoccupation with weight among women than among men is consistent with previous research, ${ }^{17-19}$ and could be explained in terms of gender differences in opportunities to gain weight and the perceived social importance of gaining weight. Generally, more women than men are full-time homemakers and, irrespective of their paid employment status, are more frequently responsible for purchasing food, planning meals, and preparing meals. This means that they spend more time thinking about food and working with food, making it a more readily available substitute for smoking. At the same time women are more concerned about body image and more inclined than men to believe they are overweight. ${ }^{20}$ Further, for practical purposes, it is interesting to note that, despite the common finding that fear of weight gain inhibits women's quitting, ${ }^{18}$ the desire to lose weight was not a major factor thwarting the attempts of ex-smokers to retain their exsmoker status. This suggests that concerns about the availability of food and the possibility of gaining weight when giving up smoking are common, but that such fears are relatively unlikely to be realised by the majority of female ex-smokers.

On the other hand, the 1986 Adult Use of Tobacco Survey of 13000 US residents found that weight gain or fear of weight gain did play an important role in relapse among many exsmokers. This survey found that $27 \%$ of current smokers who had tried to quit reported that "actual weight gain" was a "very important" or "somewhat important" reason why they resumed smoking, and $22 \%$ said that "the possibility of gaining weight" was an important reason for their relapse. ${ }^{21}$

Based on a review of previously published studies, the 1990 report of the US Surgeon General estimated that the average postcessation weight gain is five pounds $(2.3 \mathrm{~kg}$ ), and that less than $4 \%$ of those who quit smoking gain more than 20 pounds $(9.0 \mathrm{~kg}){ }^{21}$ These findings need to be more widely publicised to counter the exaggerated fear of postcessation weight gain that many smokers may have. Because such fear will persist in many smokers, counselling on weight control strategies and exercise should be a part of smoking cessation programmes.

\section{SUPPORT FOR QUITTING}

The gender differences which emerge in relation to perceived support for quitting are essentially consistent with the argument that smoking status is more relevant than gender in influencing attitudes in relation to smoking. More men than women perceived their spouse or partner as being supportive of their attempt to stop smoking. It is likely that these spouses or partners were women who had never been smokers. As non-smokers they are likely to be supportive of their spouses' attempt to stop smoking. Further, as women are more often homemakers and mothers, they are seen as being more nurturant than males, who less frequently occupy these roles. This argument is consistent with the finding that, for both male and female smokers, mothers and daughters are seen as more supportive of quitting than are fathers and sons.

Similarly, the finding that more men than women perceive their workmates as being supportive of their giving up may be partly explained by the fact that more male smokers are in paid employment (or full-time employment $)^{13}$ and in fact have workmates. Men are more likely to spend non-work time with their workmates, while many employed women rush home to attend to the duties associated with their maternal or homemaker roles.

\section{QUIT ATTEMPTS}

There were no gender differences in the reported number of quit attempts. This is consistent with recent US data. ${ }^{17}$ 


\section{RESUMPTION AFTER QUITTING}

There were gender differences in the frequency of volunteering each of six reasons/contexts for resuming smoking after an attempt to stop smoking. These differences are all consistent with the situational explanation of gender differences. Men are more likely to resume smoking when drinking alcohol or because of job worries. There is ample evidence that men drink more alcohol ${ }^{22}$ and more frequently use alcohol as a means of coping with stress. ${ }^{23}$ Generally, in Australia, men rather than women have a drink with their workmates after work, and more men than women are in the paid workforce and in the areas of employment $^{13}$ where they may experience workrelated stress. Taken together, these things suggest that men are more likely to have the opportunity to be offered, and accept, a cigarette while drinking alcohol. On the other hand, women were more likely to resume smoking when drinking coffee, in response to a family argument (presumably as a means of reducing stress), to lose weight, and in response to family illness. These situations are ones in which women are more likely to be found. Therefore, the data pertaining to relapses after stopping smoking are all consistent with the suggestion that reasons offered reflect the social situations in which women and men are found, rather than any basic psychological or physiological differences between women and men.

\section{Conclusion}

The results are consistent with the hypothesis that, in relation to smoking behaviour, the categories of smoker, ex-smoker, and neversmoker would provide more information about a person's attitudes and behaviour than would the gender-based categories of female and male. In the majority of instances the differences obtained between the smoking categories were markedly greater than those between the gender categories. Further, the virtual absence of interactions between smoking status and gender suggests that these two sets of categories operate independently.

In Australia and countries like it, differences between women and men in relation to attitudes and smoking behaviour reflect the situations in which women and men are more commonly located within the social environment. These findings lend support to the argument that the observed gender differences are a by-product of gender-related social experiences rather than a direct effect of gender. Most smokers have similar attitudes to smoking. Therefore, in countries similar to Australia, educational programmes designed to discourage young people from starting to smoke, or to assist smokers in stopping smok- ing, can be based on psychological principles equally valid for females and males.

If our interpretation is correct, it suggests that countries which have or have had large gender differences in smoking are likely to be ones where the social roles of men and women are clearly differentiated. If these countries move to less gender-based differentiation of roles, as has been the case in countries such as the US and Australia, it is likely that smoking rates in these countries will also become more similar. One of the challenges facing societies with high male and low female rates is to try to ensure that this occurs by a reduction in the proportion of men smoking, and not by an increase in the number of women smoking, as has been the unfortunate experience in some countries.

1 Hill DJ, White VM, Gray NJ. Measures of tobacco smoking in Australia 1974-1986 by means of a standard method. Med F Aust 1988; 149: 10-2.

2 Hill DJ, White VM, Gray NJ. Australian patterns of tobacco smoking in 1989. Med $\mathcal{F}$ Aust $1991 ; 154: 797-801$.

3 Fiore MC, Novotny TE, Pierce JP, Hatziandreu EJ, Patel KM. Trends in cigarette smoking in the United Patel KM. Trends in cigarette smoking in the United
States: the changing influence of gender and race. $\mathcal{F} A M A$

4 Crofton J. Tobacco in the Third World. Thorax 1990; 45 : $164-9$

5 Grunberg NE, Winders SE, Wewers ME. Gender differences in tobacco use. Health Psychol 1991; 10: 143-53.

6 Waldron I. Patterns and causes of gender differences in smoking. Soc Sci Med 1991; 32: 989-1005.

7 Bem SL. Gender schema theory: a cognitive account of sex typing. Psychol Rev 1981; 88: 354-64.

8 Deaux K. From individual differences to social categories: analysis of a decade's research on gender. Am Psychol 1984; 39: 105-16.

9 Deaux K, Major B. Putting gender into context: an interactive model of gender-related behavior. Psychol Rev interactive model of

10 Eagly A. Sex differences in social behavior: a socialrole interpretation 1987, London: Lawrence Erlbaum

11 Kalin R, Hodgins, DC. Sex bias in judgements of occupational suitability. Can $\mathcal{f}$ Behav Sci 1984; 16, 311-25.

12 Borland R. Slip-ups and relapse in attempts to quit smoking. Addict Behav 1990; 15, 235-45.

13 Castles I. Year Book Australia, 1989. Canberra: Australian Bureau of Statistics.

14 Hill DJ. Australian patterns of tobacco smoking in 1986. Med $\mathcal{F}$ Aust $1988 ; 149: 6-10$

15 Dwyer J, Pierce JP, Hannam CD, Burke N. Evaluation of the Sydney "Quit For Life" anti-smoking campaign. Part 2: Changes in smoking prevalence. Med $\mathcal{J}$ Aust 1986; 144: $344-7$.

16 Petitti DB, Friedman GD, Kahn W. Accuracy of information on smoking habits provided by selfadministered research questionnaires. Am $\mathcal{F}$ Public Health 1981; 71: 308-11.

17 Pirie PL, Murray DM, Luepker RV. Gender differences in cigarette smoking and quitting in a cohort of young adults. Am f Public Health 1991; 81: 324-7.

18 Orlandi MA. Sex differences in smoking cessation. Women and Health 1987; 11: 237-51.

19 Wells J, Batten L. Women smoking and coping: an analysis of women's experience of stress. Health Educ F 1990; 49 : of wome

20 Fallon $\mathrm{AE}$, Rodin P. Sex differences in perceptions of desirable body shape. $\mathcal{F}$ Abnorm Psychol 1985; 94: 102-5.

21 US Department of Health and Human Services. The health benefits of smoking cessation: a report of the Surgeon General, 1990. Atlanta, Georgia: Centers for Disease Control, Office on Smoking and Health, 1990. (DHHS Publication No (CDC) 90-8416.)

22 Johnson PB. Sex differences, women's roles and alcohol use: Preliminary natural data. $\mathcal{F}$ Social Issues 1982; 38 : 93-116.

23 Revell AD, Warburton DM, Wesnes $\mathrm{K}$. Smoking as a coping strategy. Addict Behav 1985; 10: 209-224. 